\title{
Diablerie: In memoriam Manuel João Gomes
}

\author{
JOSÉ ALBERTO FERREIRA
}

In this brief essay I propose a reflection on the work of Manuel João Gomes, a theater critic for many considered an exemplum, whose critical magisterium is presented here interspersed with the works of editor, translator and author. We will also reflect on theatre criticism in Portugal, honoring one of its most outstanding cultivators.

THEATRE CRITIC / MANUEL JOÃO GOMES / PORTUGUESE THEATRE HISTORY / EDITION

1. DIABLERIE, OU O HOMEM QUE CONHECIA O DIABO...

Apresentar uma reflexão em torno da figura de Manuel João Gomes levou-me a identificar três vertentes da sua actividade, consequentes com o seu percurso, com a obra que nos legou e com o magistério crítico que exerceu num regime que tendemos a situar como exemplar. Num texto em que lhe presta sentida homenagem, Luis Miguel Cintra afirmou que «nesta terra pequena, [os críticos de teatro] acabaram por ser nossos especiais companheiros na luta que ao longo de muitos anos fomos travando para que o teatro existisse na cidade», e lembrou que o Manuel João Gomes foi «talvez de todos os críticos, o mais discreto, o mais modesto, o mais militante. Foi na crítica de teatro uma espécie de doce guerrilheiro» (Cintra, 2007).

A primeira vertente a considerar é a de editor de textos, o mais das vezes ligados à história e cultura portuguesa e europeia e, por regra, ocupando nesse sistema cultural uma posição claramente marginal. Refiro-me aos textos do âmbito do fantástico, que editou na «Colecção Meia-Noite», da Arcádia. Considere-se também a sua colaboração com as edições Ribeiro de Mello/Afrodite, como editor de textos como O Processo dos Távoras (hoje uma raridade bibliográfica), editado em 1974; Feiticeiras, de Jules Michelet (também de 1974), ou ainda a Nova recolha de provérbios e outros lugares comuns portugueses (com mais de uma edição). 
Entre os muitos cultores do horror e do fantástico que editou, traduziu e comentou, uma linha de trabalho da qual resultou um corpus reconhecível, encontramos os 6 contos frenéticos de Álvaro do Carvalhal (Arcádia, 1978), o jovem autor oitocentista que Manoel de Oliveira adapta para cinema no extraordinário Os Canibais (conto homónimo de Carvalhal incluído por Manuel João Gomes nesse volume). Encontramos também, entre tantos outros, reunidos nos vários volumes da «Colecção Meia-Noite» (da Arcádia), textos de Cazotte e Stevenson, Apollinaire, Lautréamont, Schwob, Oscar Wilde, Lovecraft, Alexandre Dumas pai, António José da Silva. Uma reunião de autores que cultiva o humor negro, o fantástico, o terror e o sobrenatural, a erudição e a tradição europeia, quase sempre com a figura do diabo em primeiro plano (sobre as edições Fernando Ribeiro de Mello/Afrodite, veja-se o excelente volume que editou Pedro Piedade Marques em 2015).

Noutro campo editorial, o da tradução, Manuel João Gomes firmou créditos de tradutor comprometido e militante. Com efeito, saem da sua mão traduções de um certo tipo de textos e de autores. Dele temos traduções cuidadas e rigorosas de Emma Santos, André Breton, Marquês de Sade, Louis-Ferdinand Céline, Henry David Thoreau, Denis Diderot, Antonin Artaud, muitos dos quais traduziu com o objectivo de divulgar e garantir o acesso a textos de mais rara circulação, como aconteceu com o Suplemento à viagem de Bougainville, de Diderot (Lisboa, \&etc.), bem como com as suas traduções militantes de Artaud - das Mensagens Revolucionárias ao iconoclasta Para acabar de vez com o juízo de Deus, seguido de $O$ teatro da crueldade (que traduziu para a \&etc. em 1975, com Luíza Neto Jorge, sua companheira).

Por fim, creio que é necessário referir o autor que Manuel João Gomes também foi. Se por um lado foi dramaturgista (ocasional) e tradutor comprometido (como vimos), enquanto autor assinou livros como O Almanaque dos Espelhos (1980) e Os Segredos da Jacinta (1982), duas descabeladas incursões no reino da paródia (em sentido preciso, como o estabeleceu com rigor Hutcheon [1989]). Trata-se de uma escrita torrencial, pautada pelas alusões, citações, invenções e variações que a mítica \&etc. deu a lume em cuidadas edições com tiragens de 1000 e 2000 exemplares, respectivamente (números que hoje seriam de todo improváveis, se não mesmo impossíveis).

Acrescento a tudo isto uma nota mais pessoal: quando busco na minha biblioteca os livros do Manuel João Gomes, que seguro nas mãos e retiro das estantes, para manusear, reler aqui e ali, encontrar notas, 
papelinhos, sublinhados e outras memórias de leituras perdidas, verifico que muitos deles foram adquiridos n'A Crise - livraria bar edições, de Coimbra. Uma livraria-editora alternativa cuja presença marcou os anos oitenta (e os meus anos oitenta) como ponto de encontro entre jovens leitores e estes autores das margens, traduzidos, comentados, anotados, e também lidos e conversados nos cadeirões da livraria ou nos cafés da cidade. Um lugar alternativo para um autor alternativo?

\section{O HOMEM QUE GOSTAVA DE LISTAS}

Senhor de uma cultura assinalável, o que tão bem serve na oficina da crítica teatral como na de tradutor e autor, Manuel João Gomes prepara e faz acompanhar de listas muitos dos livros de que é tradutor-antologiador-editor-apresentador-anotador. As Mensagens Revolucionárias (1980) são acompanhadas de uma lista de título significativo:

Viagem alfabética ao México e à revolução na companhia de Artaud, actor e poeta surrealista, à procura da verdadeira cultura primitiva mexicana, a fim de a transplantar para a Europa, com ela intentando resolver os problemas que então, como hoje, se punham à nossa Velha Civilização.

É um exemplo bem demonstrativo das relações entre autor, tradutor, e autor traduzido, entre antologiador e obra antologiada. No caso da «Colecção Meia-Noite» (Arcádia), as listas ocupam em cada livro o Átrio, fórmula de organização dos volumes que desempenha uma função prologal, mas os volumes incluem muitas vezes outros complementos, ou apêndices em lista, num jogo que procura dar ao leitor um território de pistas de leitura tão ou mais saturado que o do texto original.

Por vezes, estas listas procedem de $a$ a $z$, aproximando-se do registo dicionarístico, manifestando por essa via, como lembrava Michel Butor, uma muito razoável condição literária:

Os livros mais espalhados e de certo modo os mais úteis à nossa sociedade, sem os quais não poderíamos passar, são aqueles que consultamos, e que são feitos de maneira a podermos achar o ensinamento de que necessitamos, sem termos de os ler de ponta a ponta - os dicionários. São característicos da nossa civilização. Nenhuma sociedade, nenhum Estado moderno poderia subsistir se lhe faltasse esse objecto essencial, 
esse monumento pouco estudado que é a lista telefónica. Muitos dicionários são obras-primas das nossas literaturas. (Butor, 1968: 401)

Não é despiciendo que seja o mesmo Manuel João Gomes a fornecer esta chave, numa piscadela de olhos ao leitor-cúmplice que esta literatura permanentemente busca, desassossega e interpela. Ou talvez possamos pensar as listas de Manuel João Gomes como parte daquela vertigem das listas de que falou Umberto Eco (2009), sublinhando o lado obsessivo das listas no comportamento humano e delas distinguindo dois tipos: as listas práticas e as listas poéticas (2009: 13). E se estas listas podem ser vistas como práticas, resultantes do contexto que justifica a sua criação, elas são com maior evidência poéticas, já que nelas encontramos aquela «finalidade artística com a qual a lista» foi proposta, independentemente da «forma de arte que a exprime» (2009:113). O que poderia também apontar-se como uma poética do conhecimento, entre os objectivos enumerativos e descritivos das listas práticas e a vertigem enciclopédica das ligações propostas pelo autor-editor com os textos cuja tradução-leitura propõe.

\section{O PODER DA CRÍTICA TEATRAL}

Por fim, e neste contexto com toda a centralidade, consideremos agora o trabalho do crítico teatral, actividade que Manuel João Gomes exerceu de forma continuada, comprometida, combativa, esclarecida e informada. O seu nome deverá figurar (se não figura ainda) ao lado dos grandes nomes que marcaram a crítica portuguesa no século $\mathrm{xx}$ (de Jorge de Sena a Carlos Porto, Manuela Porto, Luiz Francisco Rebello ou Orlando Neves, para referir apenas alguns). Manuel João Gomes escreveu sempre no Público, e o espaço crítico que ali estabeleceu acompanhou de forma clara o crescendo de actividade cultural e artística que se verificou no final dos anos oitenta e ao longo dos noventa, como o crescimento do número de companhias (nomeadamente fora de Lisboa). Vera Borges (2002) identifica as seguintes quinze companhias de teatro ${ }^{1}$ fundadas nos anos

1 A mesma autora identifica as seguintes companhias, fundadas nos anos setenta, antes e depois do 25 de Abril, o que dá bem a ideia da expansão do campo a partir desse momento histórico: Teatro Experimental do Porto - TEP (Porto, 1952); Teatro Experimental de Cascais - TEC, (Cascais, 1965); Grupo 4 (Lisboa, 1967), que deu origem ao Novo Grupo (Lisboa, 1982); Comuna (Lisboa, 1972); Cornucópia (Lisboa, 1973); O Bando (Lisboa, 1974); Barraca (Lisboa, 1976); Centro Cultural de Évora (1975), que integra o teatro da Rainha e dá origem ao CENDREV (1990); Teatro de Animação de Setúba (1975); Teatro de Campolide (Lisboa, 1971), que dá origem à Companhia de Teatro de Almada (1975); Teatro Infantil de Lisboa (1976); Os Pápa-Léguas (Lisboa, 1976); Seiva Trupe (Porto, 1978) (Borges, 2002). 
oitenta (cinco em Lisboa, as restantes pelo país), além da Companhia de Teatro de Braga (1980):

Teatro em Movimento (Bragança, 1980); Trigo Limpo / ACERT (Tondela, 1980); ACAE (Lisboa, 1980); Teatro do Semeador de Portalegre (1981); GICC (Covilhã, 1981); Maizum (Lisboa, 1982); Teatro Experimental do Funchal (Madeira, 1984); Teatro de Marionetas de Lisboa (1985); Chão de Oliva (Sintra, 1986); Filandorra - Teatro do Noroeste (Vila Real, 1987); A Lanterna Mágica (Lisboa, 1988); Teatro de Marionetas do Porto (1988); Teatro da Garagem (Lisboa, 1989).

São tempos de crescimento decisivo, que se estende muito além da paisagem lisboeta, e com tendência a crescer, como a listagem dos anos noventa da mesma autora mostraria. E são também os tempos da internacionalização, com a adesão à então CEE. São os tempos dos Encontros ACARTE no teatro e na dança, com a época a desaguar nas grandes iniciativas europeias dos anos noventa, como a Lisboa 94 e a Expo 98, concretizando o ciclo «Já somos internacionais, falta sermos cosmopolitas!» (1986-1998) apontado por António Pinto Ribeiro (2009:60). E, se Manuel João Gomes acompanha este percurso com o seu olhar crítico, com a sua presença discreta e continuada - assumindo a missão de divulgar, informar, apoiar, analisar -, também se pode dizer que acompanhou o seu declínio. Com efeito, e retomando uma nota que noutro trabalho deixei sobre a problemática da crítica teatral em Portugal:

A crítica teatral viu, ao longo dos últimos vinte anos, diminuir progressivamente o seu espaço nos média e muito limitadas as condições de mobilidade dos seus agentes (quase confinados ao trabalho na capital, Lisboa, raramente no Porto). Historicamente, com a ampliação do espectro de referências estéticas que hoje dominam a cena teatral portuguesa (em sintonia com a europeia/ocidental), viu a sua condição orientadora do gosto e a sua qualidade analítica, uma e outra tradicionalmente assentes no prestígio do crítico e na distinção cultural que o seu discurso instaurava, serem paulatinamente substituídos pela diversidade de suportes, de públicos e de objectos de discurso, originando discursos críticos que supõem «comunidades interpretativas»² distintas (por vezes emergindo

2 Tomo o conceito de «comunidades interpretativas» de Stanley Fish (1980), aplicando-o ao acto de leitura crítica do espectáculo. Assim procuro evidenciar o paradoxo que vê o aumento de diversidade de formas, de discursos e de possibilidades artísticas numa arte diversa e plural (Vera Borges lembra que são teatros) ser acompanhado da diminuição de espaço crítico e da redução da espessura de discursos mediadores. 
do próprio tecido criativo). Nalguns casos, assistiu-se até à grosseira mercantilização da mediação - com jornais a limitarem o discurso crítico à existência de contrapartidas publicitárias ou à sponsorização dos eventos referenciados. Ou, ainda, aos grupos de pressão associados a circuitos de criação dominantes. (Ferreira, 2015: 124)

Este é um cenário que todos, hoje, reconhecemos nos seus contornos mais limitadores e nas suas consequências mais danosas. E o impacto que tem e terá a ausência de instâncias críticas no tecido habitado por criadores e criações contemporaneamente, só com o tempo poderá ser plenamente compreendido, analisado e avaliado.

\section{MANUEL JOÃO GOMES, CRÍTICO DE TEATRO}

Os contornos mais precisos com que procuro evidenciar o desaparecimento progressivo da crítica mais não fazem do que destacar o papel exemplar do crítico Manuel João Gomes. Sempre disponível para viajar, fosse para ver espectáculos a norte ou a sul, no interior como no litoral. Sempre capaz da responsabilidade diferenciadora do crítico, exigente com as companhias estabelecidas, generoso e pedagógico com os projectos como com o público leitor a propósito de espectáculos de estreantes ou até de amadores, não enjeitando estar em espectáculos de uns e de outros com o mesmo espírito de missão e a mesma disponibilidade.

Por razões que aqui não importam, recorro neste trabalho a um pequeno conjunto de textos de crítica escritos e publicados por Manuel João Gomes entre 1998 e 1999, dois anos particularmente intensos. O primeiro é o nosso annus mirabilis, marcado pela abertura do Museu de Serralves, pela realização da Expo de Lisboa, pela presença de artistas como Pina Bausch e Bob Wilson, uma etapa em que se confirmava também a «vocação europeia» da criação portuguesa contemporânea, mercê das políticas de Manuel Maria Carrilho e da sua equipa à frente do Ministério da Cultura.

No jornal a que Manuel João Gomes esteve sempre ligado, o Público, pontificava Eduardo Prado Coelho, com o luminoso «Fio do horizonte», espaço de comentário cronístico algum tanto mitificado. O ano de 1998 foi de intensa criação teatral, apesar de Jorge Silva Melo zurzir a fragilidade das subvenções estatais com um texto contundente publicado no Dia Mundial do Teatro desse ano e provocatoriamente intitulado «Salas fechadas». Ainda assim, quem lesse o jornal daquele ano em 
busca de um retrato do teatro nacional encontraria menos razões para desânimo. Manuel João Gomes apontava, na entrada da estação estival, a vitalidade das propostas de Verão (num texto de 20 de Julho de 1999), pontuada por produções abundantes em Lisboa e no Porto, cidade que parecia atravessar, por essa altura, um período de decisivo desenvolvimento - desde logo com os preparativos da Capital Europeia da Cultura, mas sobretudo com a emergência de novas companhias e estruturas, e com a afirmação daquelas que poucos anos antes haviam iniciado o seu percurso (Visões Úteis, Teatro Bruto, Teatro Plástico, As Boas Raparigas, entre outras).

No Público, por esta altura, a crítica de teatro contava com o contributo regular de nomes como Jorge Marmelo, Vanessa Rato, Kathleen Gomes, Rui Ferreira e Sousa, Maria José Oliveira, Graça Barbosa Ribeiro, Bárbara Reis, Óscar Faria ou Álvaro Vieira (numa listagem sem qualquer ordenação). No Expresso, pontificavam Eugénia Vasques e João Carneiro.

É sobre este pano de fundo que importa situar o trabalho do crítico conimbricense. Aquele era um tempo em que ainda havia espaço nos jornais para crítica de teatro (e dança, cinema, música, arquitectura...). Quer dizer, espaço mesmo. Por exemplo, quando publica sobre o Sertório de Racine, levado à cena pela Cornucópia, o crítico pode fazer um enquadramento histórico da peça e contextualizá-la no percurso da companhia, evidenciando as razões dramatúrgicas da proposta e contextualizando-a nas lógicas de cooperação internacional da Cornucópia. Em alguns casos, encontro mesmo exemplos de críticas a dois espectáculos em destaque na mesma página: Maria José Oliveira e Manuel João Gomes sobre Ubardo e I stand before you, naked, respectivamente, publicados a 12 de Dezembro de 1998, havendo ainda espaço para destacar um espectáculo de marionetas num texto de Óscar Faria. Noutro caso, uma página com dois textos de Manuel João Gomes, um sobre o PONTI, outro sobre Paulo Castro em Braga (5 de Dezembro de 1999, p. 33), uma espécie de contraponto (entre tipologia de produções, entre geografias culturais e de criação) que agradava francamente ao autor.

É frequente dizer-se que a crítica se faz e se vive como género jornalístico imediato, numa escrita de proximidade ou do instante, que simultaneamente dela faz «crónica do tempo presente» (como Shakespeare disse que era missão do teatro, ou do actor) e escrita sem futuro, efémera, friável, condenada à transitoriedade do (seu) mundo. Não abundam, talvez por isso, as críticas de teatro compiladas e publicadas em volume (podem lembrar-se as da autoria de Jorge de Sena, Carlos Porto ou Orlando Neves), 
e as de Manuel João Gomes seriam hoje de difícil acesso para quem as quisesse ler. Virá um dia, estou certo, em que as histórias do teatro incluirão a crítica e os críticos como parte sua, parte legítima e crucial, com as suas funções de mediação, de informação, de formação, de divulgação. Pois, apesar de a crítica ser frequentemente considerada um parente pobre da família do teatro, uma descrição sistémica desta arte não poderá, em nenhuma circunstância, descartar a sua importância e desatender da natureza documental e informativa destes textos.

O certo é que quem lesse numa perspectiva documental estes textos de Manuel João Gomes também poderia encontrar razões para se desenganar quanto à transitoriedade do texto crítico, que pensamos sempre escrito com a urgência que o jornal impunha ao autor. Isso foi verdade em muitas etapas da crítica teatral (Orlando Neves, outro esquecido da crítica portuguesa, confirma-o sem rebuço). Mas, no caso da escrita de Manuel João Gomes, e nos anos que escolhi abordar aqui, há vários exemplos do contrário. Como escrever sobre $O$ Ano do Pénis, projecto de João Grosso para o Centro Comunitário Gay e Lésbico da Rua Formosa, «um mês depois da estreia» ( 5 de Julho de 1998, p. 37). Ou escrever sobre Possibilidades, um Howard Barker dirigido por Rogério de Carvalho com As Boas Raparigas, no Porto, no último dia da apresentação (2 de Agosto de 1998, p. 21). A oportunidade era mais a da constância, da persistência e da continuidade do que da pressão do jornal. E o Manuel João Gomes sempre militou na constância, que cumpriu empenhadamente. Até cultivando outras dimensões do discurso crítico, como a polémica (por exemplo, a que ocorreu naquele ano em torno do teatro de Vale-Inclán), ou a recensão crítica (por exemplo, a do volume da Adágio que o Cendrev dedicou, em 1999, a Bertolt Brecht).

Na verdade, parece-me evidente que Manuel João Gomes sempre adoptou uma compreensão que penso poder designar como expandida do campo crítico e do campo teatral. Além dos exemplos apontados, parece-me importante assinalar o interesse do crítico perante as formas de teatro em relação directa com a televisão. Escreveu, por exemplo, sobre uma Casa de Bernarda Alba dirigida por Nuria Espert com a Lyric Theatre de Londres (e transmitida pela RTP2 a 8 de Fevereiro de 1998), ou sobre o Othello dirigido por Trevor Nunn para a BBC (6 de Julho de 1998), ou ainda sobre a Conversa da Treta, o êxito popular de António Feio e José Pedro Gomes transmitido pela SIC (2 de Janeiro de 1999). Em qualquer dos casos, Manuel João Gomes assume uma atitude crítica de desassombro rigoroso e coerente, integrando uma perspectiva didáctica e 
articulando elementos de orientação para o leitor-espectador televisivo eventual. Por exemplo, indica a existência de traduções do texto de Lorca, contextualiza a transmissão nas comemorações do centenário do dramaturgo e, com equitativo à-vontade, assinala as companhias de teatro portuguesas que terão Lorca em cena ao longo daquele ano de comemorações.

5. QUE SE ESPERA DA CRÍTICA TEATRAL HOJE?

O contexto actual, marcado pela diversidade de tipologias de espectáculo, de objectos artísticos, de linguagens, de solicitações e de comunidades, convida a considerar mais do que uma possibilidade face a uma pergunta cujo horizonte se não satisfaz numa só resposta. Respostas várias e diversas, em tempos de transformações aceleradas. Por exemplo a transformação dos jornais, que têm cada vez menos leitores. E também a dos leitores, que estão mais disponíveis para ler uma nota gratuita na agenda cultural ou na Time Out do que para procurar uma informação qualificada (sobre dramaturgos ou sobre encenadores, actores ou companhias).

Também o papel do crítico, a sua função, o seu perfil, sofreu transformações. Talvez devamos considerar que o crítico já não pode ser, como foi, uma figura tutelar, cuja isenção e carisma davam garantias éticas e legitimadoras ao leitor. Talvez o Manuel João Gomes tenha sido um desses críticos, e talvez tenha sido o último...

Acentuando as transformações dos média, nomeadamente a digitalização do jornal, assinalo também que o acesso ao já nem tanto admirável mundo novo da Web, dos social media, dos informal media, acontece tanto do lado dos públicos como do lado dos criadores, que difundem informação na Internet, divulgam comentários, entrevistas, registos e documentação vária. Ora, estas práticas introduzem variáveis importantes no campo da crítica. Não haverá aqui um efeito de deslocação para estas modalidades de mediação, com um impacto importante na produção teatral? Companhias, projectos e artistas com páginas Web, perfis em redes sociais, blogues, não geram comunidades virtuais/reais que de forma nova acompanham esses artistas, projectos, companhias? Não sugere esta complexa (e de complexidade crescente) ecologia medial a emergência de um novo tipo de discurso crítico, onde a apropriação e personalização, por parte de companhias e artistas, dos meios de 
expressão, possa dar lugar a formas críticas renovadas? Não emerge aqui o espaço da crítica-testemunho ou da crítica-debate, implicando os artistas na produção e difusão de discursos críticos, superando assim formas da crítica judicativa tradicional?

O desafio que me parece necessário enfrentar é o de gerar tipologias de discurso crítico renovadas, servidas por suportes novos. As universidades, cada vez mais atentas à crescente presença de artistas em programas de mestrado e doutoramento, aos programas de criação como investigação (practice as research) que caracterizam algumas tipologias de trabalho académico, contribuem decisivamente para uma maior formação dos discursos de artistas e criadores, articulando decisivamente o espaço de criação com o espaço crítico. Não creio que haja melhor forma de aprofundar a presença da crítica em relação com a criação artística actual. Nem forma mais exigente de prestar tributo ao crítico que aqui procurei singelamente homenagear.

\section{REFERÊNCIAS BIBLIOGRÁFICAS}

1. ObRas de MANUEl JoÃo Gomes

1980 Almanaque dos Espelhos, Lisboa, \&etc.

1982 Os Segredos da Jacinta, Lisboa, \&etc.

2. MANUEl JoÃo GoMES (ORGANIZAÇÃo)

1975 Para acabar de vez com o juízo de Deus, seguido de O teatro da crueldade, Lisboa, \&etc. (com Luíza Neto Jorge)

1976 histórias de terror mais 3, Lisboa, Arcádia

8 ou nove histórias de almas penadas, escritas por Alexandre Dumas pai, Lisboa, Arcádia 15 histórias supersticiosas, Lisboa, Arcádia

19772 histórias malditas, atribuídas a António José da Silva, o Judeu, Lisboa, Arcádia A história do diabo enamorado de Cazotte, Lisboa, Arcádia

19786 contos frenéticos escritos por Álvaro do Carvalhal, Lisboa, Arcádia

1979 Um homem que casou com uma sereia e uma mulher que casou com um crocodilo, Lisboa, Arcádia

1980 Mensagens Revolucionárias, de Antonin Artaud, Lisboa, \&etc.

1984 Suplemento à viagem de Bougainville, de Diderot, Lisboa, \&etc.

$1988^{2} \quad$ Nova recolha de provérbios portugueses e outros lugares-comuns, Lisboa, Fernando Ribeiro de Mello/Edições Afrodite (1974)

\section{BIBLIOGRAFIA CITADA}

BORGES, Vera (2002), «Artistas em rede ou artistas sem rede? Reflexões sobre o teatro em Portugal», Sociologia, Problemas e Práticas, 40, pp. 87-106, http://www.scielo.mec.pt/scielo.php?script=sci_arttext\&pid=So87365292002000300006. 
BUt OR, M. (1968), Repertoire III, Paris, Minuit.

CINTRA, Luis Miguel (2007), «Manuel João Gomes, um crítico de teatro diferente», Público, 12 de Fevereiro.

E CO, Umberto (2009), A Vertigem das Listas, Lisboa, Difel.

FERREIRA, José Alberto (2015), Da Vida das Marionetas: Ensaios sobre os Bonecos de Santo Aleixo, Lajes do Pico, Companhia das Ilhas.

FISH, Stanley (1980), Is there a text in this class? The authority of interpretive communities, Cambridge, MA, Harvard (trad. it.: C'è un testo in questa classe? L'interpretazione nella critica letteraria e nell'insegnamento, Turim, Einaudi, 1987).

Hutche on, Linda (1989) A Theory of Parody, Nova Iorque e Londres, Methuen (trad. port.: Uma Teoria da Paródia, Lisboa, Edições 70, 1985).

MARQUES, Pedro Piedade (2015), Editor contra: Fernando Ribeiro de Mello e a Afrodite, Lisboa, Montag.

RIBEIRo, António Pinto (2009), À Procura da Escala: Cinco exercícios disciplinados sobre cultura contemporânea, Lisboa, Cotovia.

\section{JOSÉ ALBERTO FERREIRA}

Docente no Departamento de Artes Cénicas da Escola de Artes da Universidade de Évora. Membro do Conselho Directivo do Centro de História de Arte e Investigação Artística (CHAIA) da Universidade de Évora, onde é membro colaborador e integra vários grupos de investigação na área do teatro e da curadoria. Doutorando na Universidade de Sorbonne (Paris 1), com um projecto em torno da problemática da documentação e arquivo nas artes performativas. Publicou, entre outros, Uma Discreta Invençam (2004), sobre Gil Vicente; Da Vida das Marionetas: Ensaios sobre os Bonecos de Santo Aleixo (2015). Editou e co-editou vários títulos, de que destaca Escrita na Paisagem (Porto, Mimesis), e a edição dos textos dos Bonecos de Santo Aleixo: Autos, Passos e Bailinhos (2007). Fundou e dirigiu o festival Escrita na Paisagem (2004-2012). Director artístico do Centro de Arte e Cultura da Fundação Eugénio de Almeida. 